\title{
Thermal behavior evaluation of ventilated roof under summer and winter conditions
}

\author{
Vincenzo Bianco ${ }^{1}$, Alessandra Diana $^{1 *}$, Oronzio Manca $^{2}$, Sergio Nardini ${ }^{2}$ \\ ${ }^{1}$ Dipartimento di Ingegneria Meccanica, Energetica, Gestionale e dei Trasporti, Università degli \\ Studi di Genova, Genova (GE) 16126, Italy \\ 2 Dipartimento di Ingegneria Industriale e dell'Informazione, Università degli Studi della \\ Campania "Luigi Vanvitelli”, Aversa (CE) 81031, Italy
}

Email: dialex.ad@gmail.com

\begin{abstract}
One of the European Directive priorities is the development of new strategies for "very low energy buildings". In regions with high level of solar radiation, ventilation allows the cooling load during summer period and contributes to the reduction of the energy needs of buildings. The most important advantages are the reduction of the heat fluxes transmitted by the structures exposed to solar radiation, thanks to the combined effect of shading surfaces and heat removed by the air flow rate within the ventilated air gap.

This paper illustrates a numerical investigation on a prototypal ventilated roof for residential use. The investigation is performed in order to evaluate thermofluidodynamic behaviors of the ventilated roof as a function of the different conditions applied on the top wall and the bottom wall of the ventilated cavity in summer and winter regimes. Different values of heat fluxes are applied on the top wall of the ventilated cavity to simulate typical summer and winter days conditions, whereas the bottom wall is assumed isothermal and different values of wall temperature are considered. The problem is solved by means of the commercial code Ansys-Fluent. Results are given in terms of temperature and velocity distributions, air velocity and temperature profiles along different longitudinal and cross sections of the ventilated layer in order to estimate differences between analyzed conditions.
\end{abstract}

Keywords: Ventilated Roof, Numerical Investigation, Summer, Winter Conditions, Energy Saving, Fluent.

\section{INTRODUCTION}

The development of new strategies for "very low energy buildings" is a priority in European Directives, for the improvement of building performance requirements. The main goal is the reduction of energy consumptions caused by the heat flux transmitted through buildings envelope for residential and commercial uses. In Mediterranean regions, characterized by a high level of solar radiation, the analysis of energy buildings demand is mainly ascribed to environmental conditioning. Local climate effects depend on orientation and inclination of building surfaces and climatic conditions change depending on seasons and territories, so the top cover insulation is very important to reduce energy use. The roof design is fundamental to respect comfort and energy saving, considering that, in winter period, the top cover should contain heat losses, and in summer period, the top cover should reduce heat gain from the environment. A ventilated roof has a good configuration for energy purposes [1]. It is formed by a series of layers, composed by several materials, and, in particular, a ventilation cavity goes from the eaves to the ridge, so air can flow along the channel for the entire length of the roof.
Thermal conditions and geometrical parameters (air gap height, effect of the ridge, and inclination of the slab) influence cooling effect of ventilation in the roof cavity and these parameters are tested under real climatic conditions and are numerically verified in [2-4]. Particular roof systems in naturally ventilated residential buildings use passive methods to reduce room cooling load in hot and humid climate $[5,6]$. In [7], several roof constructions under continuously airconditioned and non-acclimatized regimes are analyzed to find the suitable roof configuration for warm climates in terms of thermal users' comfort. In [8, 9], double-skin roofs are numerically analyzed and results show they are an emerging solution for passive cooling of buildings in tropical climate. In [10], a full scale ventilated roof component is studied under real climatic condition and its performances are particularly significant in summer period. In fact, ventilation cavity reduces cooling load and building energy demand [11] in summer, due to the surface shading and heat removed by the air flow. Ventilated roof performances are more remarkable than conventional roof in both summer and winter conditions $[12,13]$. Ventilated roof performances can be improved using 
upgrading systems as a function of different effects of summer and winter regimes [14-17].

This paper illustrates a numerical investigation on a prototypal ventilated roof for residential use. Due to geometric and thermal symmetry, the system has been studied considering a single side of the pitched roof. The investigation is performed in order to evaluate thermofluidodynamic behaviors of the ventilated roof as a function of the different conditions applied on the top wall and the bottom wall of the ventilated cavity in summer and winter regimes. Different values of heat fluxes are applied on the top wall of the ventilated cavity to simulate the conditions of typical summer and winter days, whereas the bottom wall is assumed isothermal and different values of wall temperature are considered. The problem is solved by means of the commercial code Ansys-Fluent and results are performed for different values of the heat flux applied on the top wall of the ventilated roof. Results are given in terms of temperature and pressure distributions, air velocity and temperature profiles along different longitudinal and cross sections of the ventilated layer in order to estimate the differences between the various conditions.

\section{MATHEMATICAL MODEL}

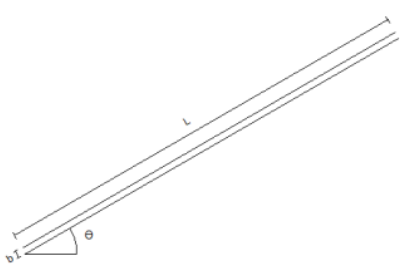

Figure 1. Ventilated channel

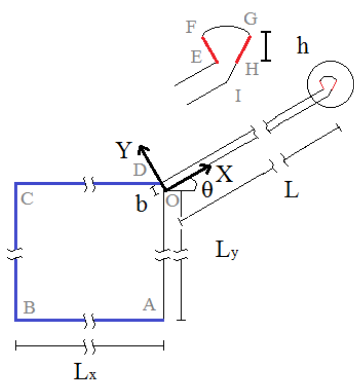

Figure 2. Computational domain

A ventilated roof is an optimal configuration for building insulation and it is composed by layers of several materials combined conveniently. The physical domain under investigation is two-dimensional and its configuration is geometrically and thermally symmetry, so a single side of the roof is considered, as shown in Figure 1. Figure 2 shows that the computational domain has finite dimensions and it is composed by the ventilated channel and two storages located at the inlet and the outlet of the channel. The two storages are useful to know what happens near the region of the thermal disturbance caused by the heat applied on the upper layer of the cavity to simulate the free-stream condition of the flow. The channel has a length, $\mathrm{L}$, equal to $6.00 \mathrm{~m}$, an inclination, $\theta$, equal to $30^{\circ}$ and a width, $\mathrm{b}$, equal to $0.10 \mathrm{~m}$. Inlet storage dimensions are $\mathrm{Lx}=\mathrm{Ly}=3 \mathrm{~m}$, equal to the average height of a floor. Outlet storage is characterized by the exit section of the channel and the height of the ridge, $\mathrm{h}$, is equal to $0.10 \mathrm{~m}$.

The governing equations of the simulation are: mass conservation, momentum equation and energy conservation [18]. It is assumed that the flow in the channel is twodimensional, the regime is steady state turbulent, viscous dissipations are negligible and thermophysical properties are constant with temperature, except for density (Boussinesq approximation), which gives rise to buoyancy forces. Air is the working fluid and its thermophysical properties are calculated at the operative temperature.

\section{NUMERICAL SOLUTION}

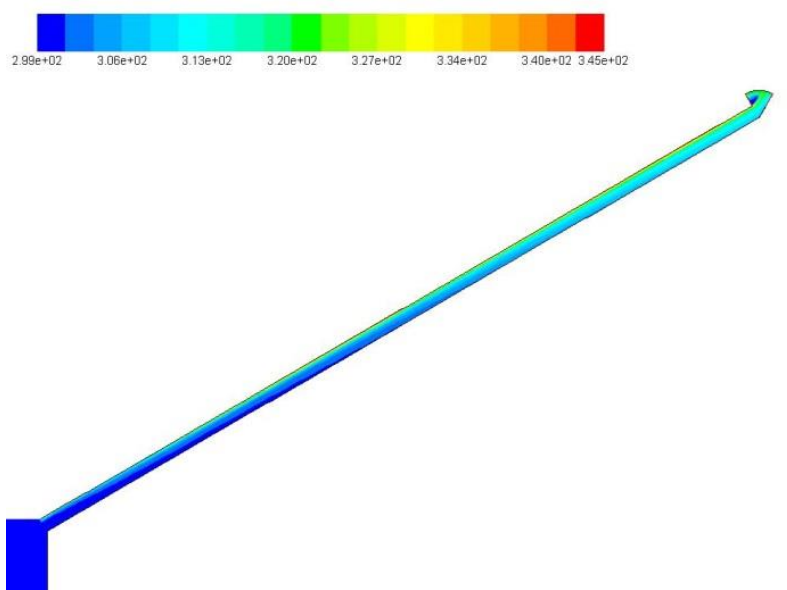

(a) Air temperature field
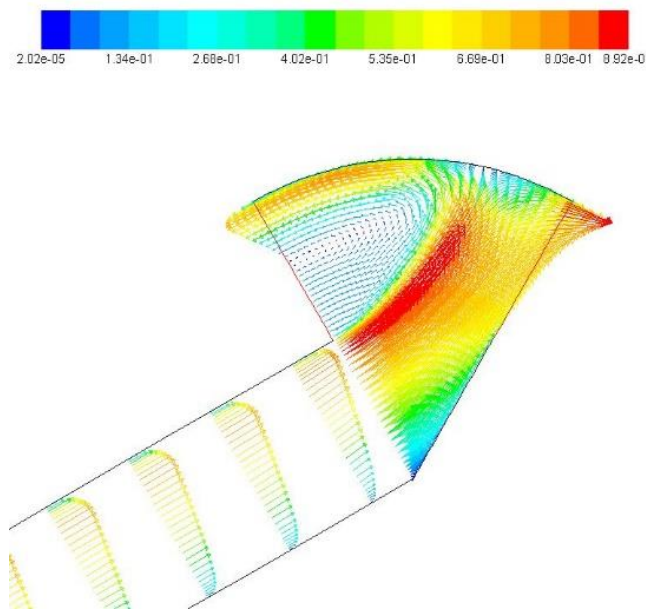

(b) Velocity vectors in outlet reservoir

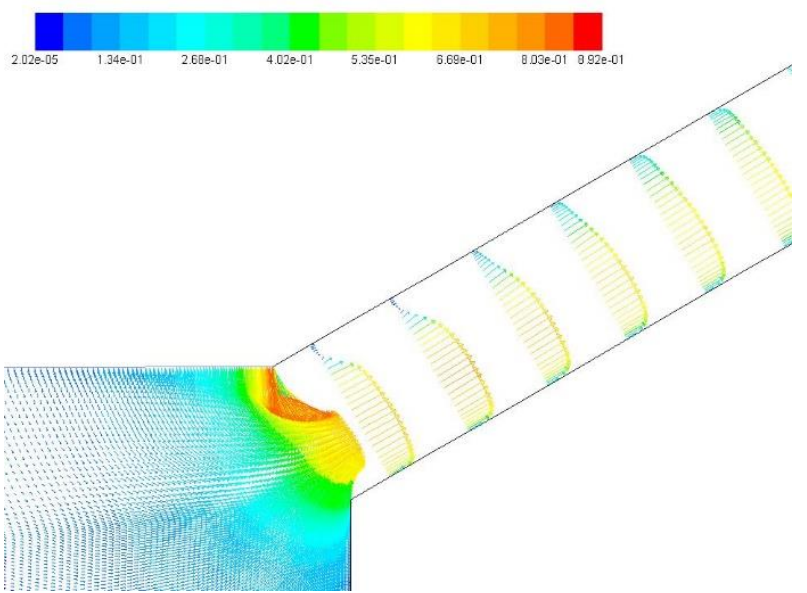

(c) Velocity vectors in inlet reservoir

Figure 3. Summer configuration at 12:00 


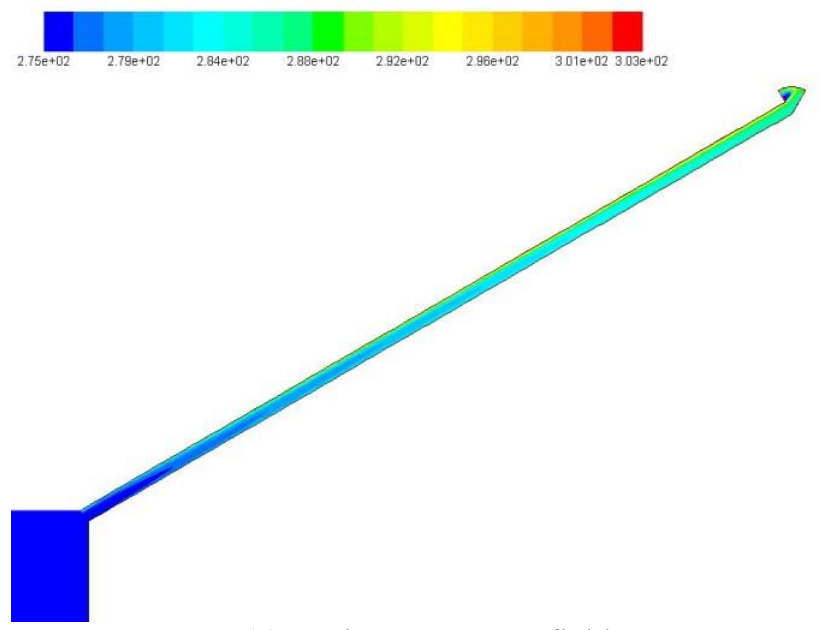

(a) Air temperature field
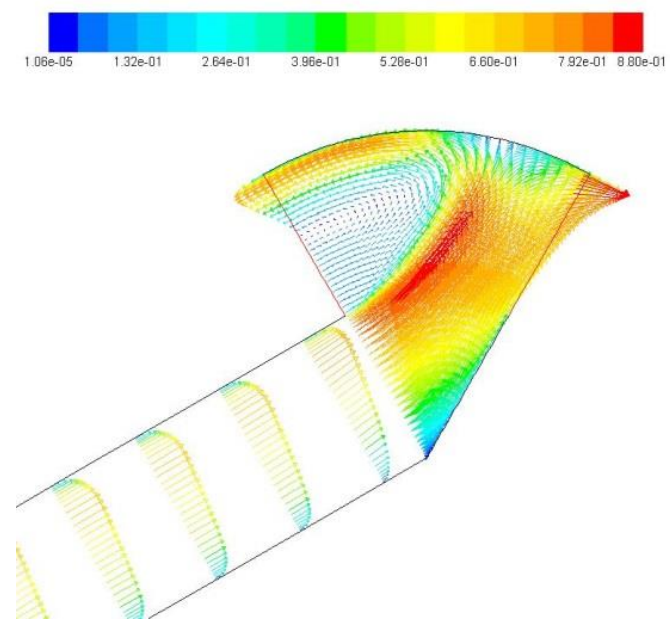

(b) Velocity vectors in outlet reservoir

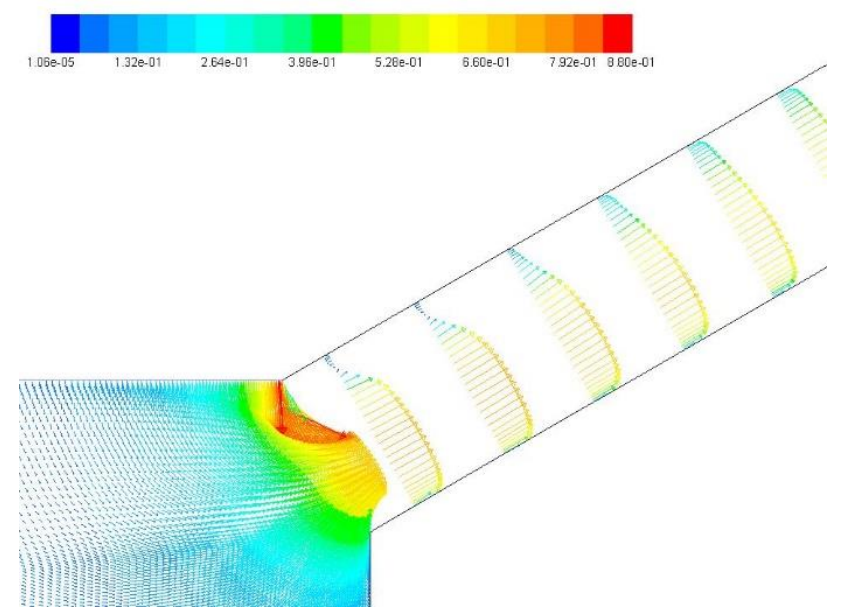

(c) Velocity vectors in inlet reservoir

Figure 4. Winter configuration at 12:00

Governing equations characterizing this thermo-physical analysis are coupled, non-linear and partial differential and their numerical solutions are obtained using the commercial code Ansys-Fluent 12.2 [19] by the finite volume method.

The numerical model used in simulations is an inclined channel, with the upper line and the bottom line simulating respectively the properties of all layers above and under the ventilated channel. In this work, two regimes are studied: summer condition and winter condition. They are numerically simulated thanks to the following boundary condition.
In summer, the operative temperature is equal to $300 \mathrm{~K}$. The bottom wall of the ventilated channel is simulated as isothermal, with $\mathrm{T}=298 \mathrm{~K}$ (optimal ambient condition in summer). In winter, the operative temperature is equal to $275 \mathrm{~K}$. The bottom wall of the ventilated channel is simulated as isothermal, with $\mathrm{T}=293 \mathrm{~K}$ (optimal ambient condition in winter). On the top wall of the cavity, a uniform heat flux is applied and its values depends on the day hours: in a typical summer day, significative heat flux values are reported from 9:00 to 18:00; in a typical winter day, significative heat flux values are reported from 9:00 to 16:00. Values are obtained thanks to the database PVGIS-CMSAF [20].

Furthermore, the bottom wall of the ventilated channel simulates the properties of structure layers under the cavity and the top wall of the ventilated channel simulates the properties of structure layers above the cavity.

The geometric model and the mesh of the computational domain are realized thanks to the software Gambit [21]. In particular, to create the mesh, several grids were realized and compared depending on Richardson's extrapolation equation [18], so the chosen grid counts 228427 calculation cells. The choice of the mesh used for simulations, depends on the right compromise between the accuracy of the simulation and calculation time.

\section{RESULTS AND DISCUSSION}

The objective of this work is to study the thermal and fluid dynamic behaviors of a ventilated roof in summer and winter regimes. In summer conditions, ten cases are analyzed, varying heat flux value from $667 \mathrm{~W} / \mathrm{m}^{2} \mathrm{~K}$ at 9:00 to $85 \mathrm{~W} / \mathrm{m}^{2} \mathrm{~K}$ at 18:00. In winter conditions, eight cases are analyzed, varying heat flux value from $310 \mathrm{~W} / \mathrm{m}^{2} \mathrm{~K}$ at 9:00 to $81 \mathrm{~W} / \mathrm{m}^{2} \mathrm{~K}$ at 16:00. In the following, for brevity, temperature fields and velocity vectors are reported for two cases, to analyze the seasonal behavior of the ventilated roof. In particular, in summer condition, $\mathrm{q}_{\mathrm{s}}=862 \mathrm{~W} / \mathrm{m}^{2} \mathrm{~K}$ at $12: 00$; in winter condition, $\mathrm{q}_{\mathrm{w}}=478 \mathrm{~W} / \mathrm{m}^{2} \mathrm{~K}$ at 12:00.

Figure 3(a) reports air temperature field in summer conditions, showing how heat transfer and air flow are influenced by heat flux applied on the top wall of the cavity. Temperature values rise in the ventilated channel with the distance from the inlet section, reaching the maximum on the top wall of the cavity, with $\mathrm{T}=345 \mathrm{~K}$.

Figures 3(b) and 3(c) show velocity values are higher near the inlet and outlet section of the channel because of the air heating velocity vectors in outlet and inlet sections. Velocity vectors highlight a vortex increasing values in proximity of the ridge in the outlet reservoir and the maximum velocity value is equal to $0.891 \mathrm{~m} / \mathrm{s}$.

In winter conditions, air temperature field and velocity vectors show the same trend: the heat flux applied on the top wall of the cavity influences heat transfer and air flow. In Figures 4(a) temperature values rise with the distance from the inlet section; the maximum is reached on the top wall of the cavity, near the outlet section, with $\mathrm{T}=303 \mathrm{~K}$. Figures 4(a) and 4(b) show velocity grows in the channel with the distance from the inlet section because of the air heating and, in proximity of the ridge, velocity vectors highlight a vortex, where values are maximum, equal to $0.880 \mathrm{~m} / \mathrm{s}$. 


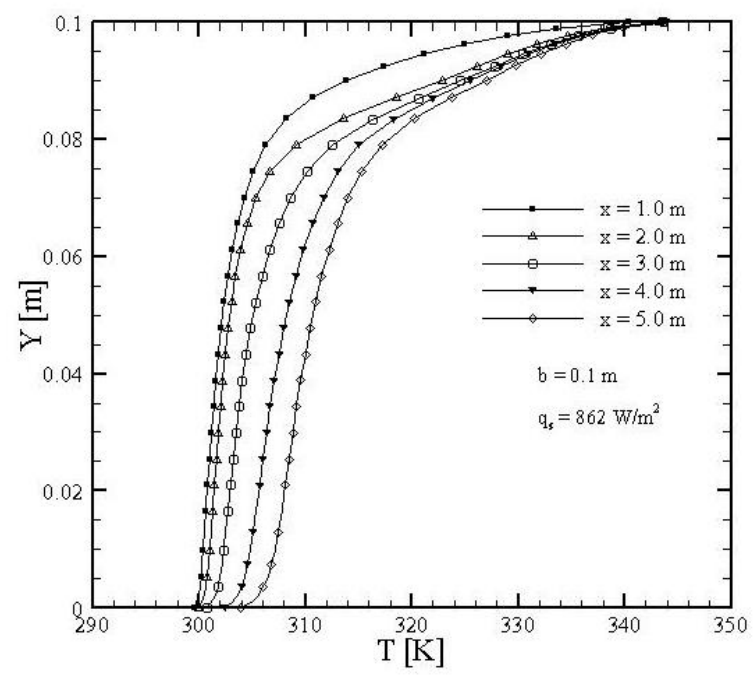

(a) Summer configuration

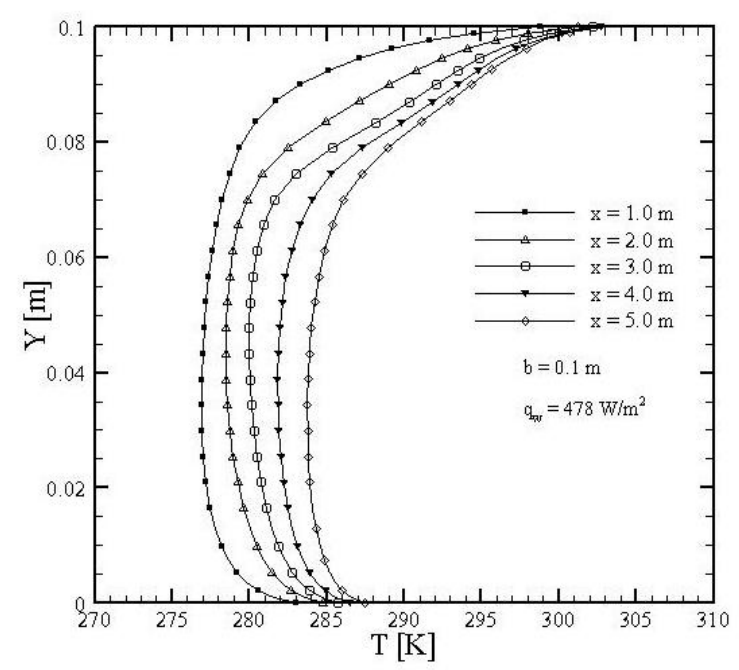

(b) Winter configuration

Figure 5. Temperature profiles in cross sections at 12:00

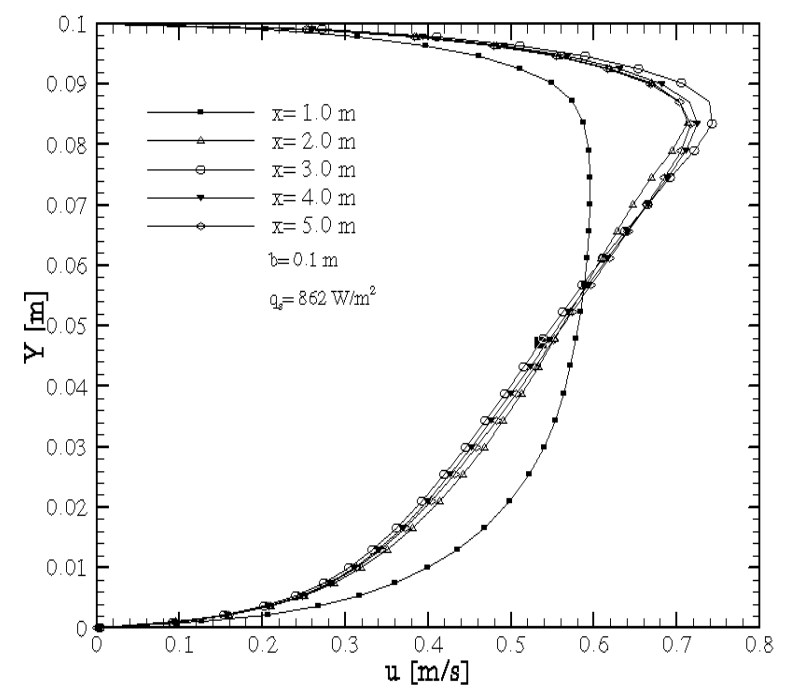

(a) Summer configuration

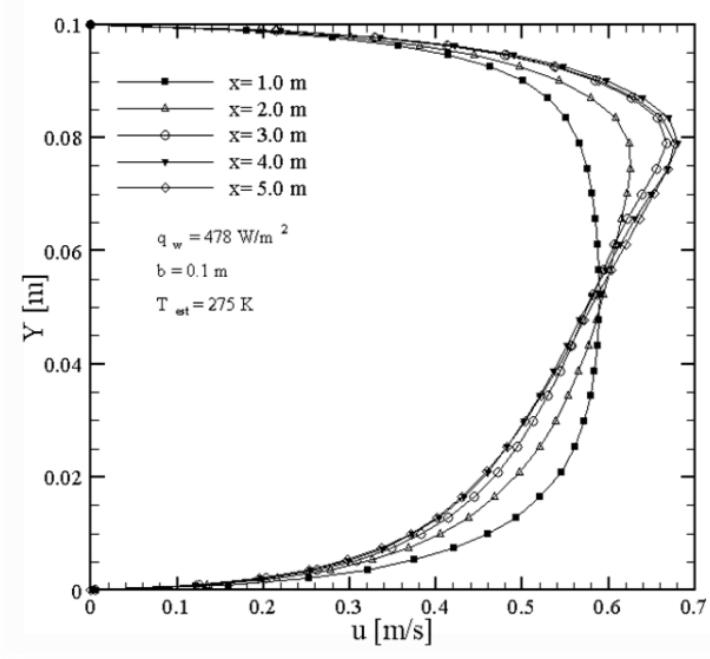

(b) Winter configuration

Figure 6. Velocity profiles in cross sections at 12:00

Considering five channel section, placed at $1 \mathrm{~m}, 2 \mathrm{~m}, 3 \mathrm{~m}$, $4 \mathrm{~m}$ and $5 \mathrm{~m}$ from the entrance, temperature profiles and velocity profile in cross sections are shown at 12:00 in summer and winter conditions.

In summer conditions, Figure 5(a) shows temperature values grow in the cavity and they are higher in proximity of the top wall, because part of the heat conveys near the cover and the temperature rise toward the top of the roof. In winter conditions, due to lower ambient temperature and heat flux applied on the top wall, Figure 5 (b) shows temperature values decrease along X-direction at first, then they grow and reach the maximum on the top wall.

In summer conditions, Figure 6(a) shows velocity values grow in the cavity and they are higher near the hot upper wall, where the effect of the heating is more pronounced. The maximum velocity value is equal to $0.75 \mathrm{~m} / \mathrm{s}$. In Figure 6 (b), in winter conditions, velocity values show the same trend, but the maximum value is equal to $0.68 \mathrm{~m} / \mathrm{s}$.

In the following, a comparison between summer and winter configurations is reported: results are given in terms of air velocity and temperature profiles along the axis of the channel.

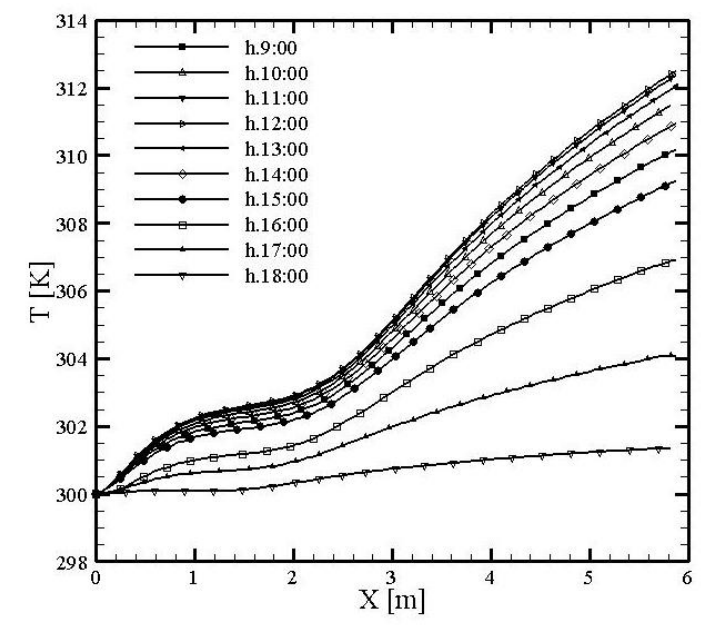

(a) Summer configuration 


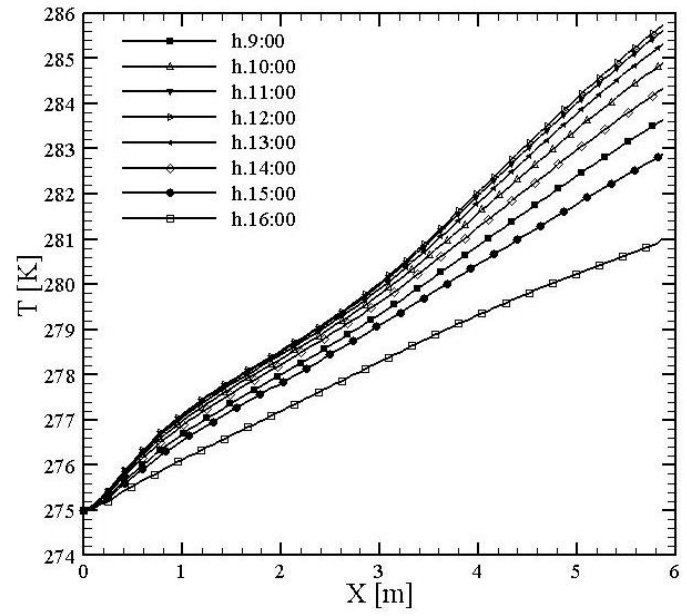

(b) Winter configuration

Figure 7. Temperature profiles in center line

Figures 7(a) and 7(b) show temperature trend along the axis of the channel in summer and winter conditions. All the profiles increase along the channel and mainly in the lower zone of the channel. In the central zone of the channel, temperature values increase about linearly.

In summer, the profile has a more pronounced fluctuation, but the growth is faster. The maximum temperature value is reached at 12:00 in both summer and winter condition.

Figures 8(a) and 8(b) show temperature profiles along the top wall of the channel in summer and winter conditions. In the inlet section, values are lower, then all the profiles increase along the channel and wall temperature values are higher in the outlet section of the channel. In summer regime, values reach the maximum at 12:00, when the heat flux is equal to $862 \mathrm{~W} / \mathrm{m}^{2}$, and it is equal to $345 \mathrm{~K}$. In winter regime, values reach the minimum at 12:00, when the heat flux is equal to 478 $\mathrm{W} / \mathrm{m}^{2}$, and it is equal to about $303 \mathrm{~K}$.

Figures 9 (a) and 9 (b) show velocity trend along the axis of the channel in summer and winter conditions. In the inlet section, values decrease, then they rise reaching a lower value in the outlet section. In summer regime, values reach the maximum at 12:00, when heat flux is equal to $862 \mathrm{~W} / \mathrm{m}^{2}$. In winter regime, velocity values reach the minimum at 16:00 when heat flux is equal to $245 \mathrm{~W} / \mathrm{m}^{2}$. When heat flux is smaller, values oscillations are less evident.

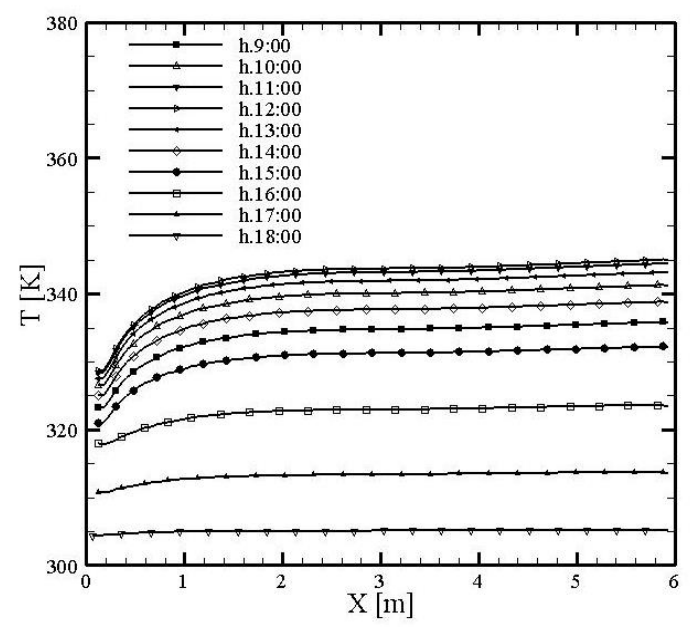

(a) Summer configuration

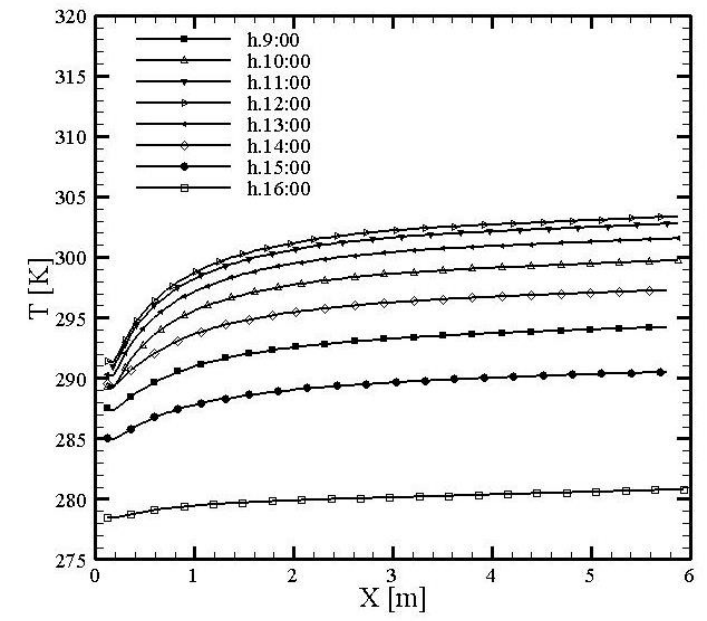

(b) Winter configuration

Figure 8. Temperature profiles along the top wall

In Tables 1 and 2, some thermofluidodynamic characteristics are described for summer and winter condition respectively. First of all, heat fluxes are reported for each hour of the day. The mass flow rate $\mathrm{M}$ indicates the mass of air which passes in the ventilated channel per unit of time. $u_{\text {avg }}$ and $u_{\max }$ are, respectively, the average and the maximum values of the velocity in the ventilated channel. $T_{\text {avg }}$ is the average value of the temperature in the exit section of the channel. $T_{\text {havg }}$ is the average value of the temperature relative to the heated surface of the ventilated channel. $T_{\max }$ is the maximum value of the temperature in the channel.

Finally, next figures show the trend of values reported in Tables 1 and 2 .

Figures 10(a) and 10(b) show the trends of average and maximum temperature values in the channel. Temperature values are relative to the ambient temperature $T_{s}$ in summer condition and to $T_{w}$ in winter conditions. It is shown that values rise when the heat flux is higher and they decrease when the heat flux is lower. In both summer and winter configuration, maximum values are reached at 12:00.

The mass flow rate shows the same qualitative trend, as reported in Figure 11, in summer and winter conditions, and maximum values are reached when the heat flux is higher.

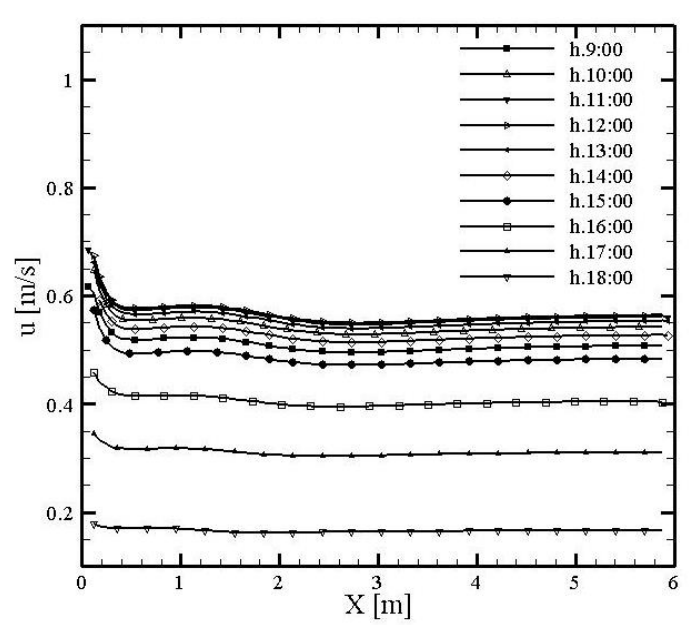

(a) Summer configuration 


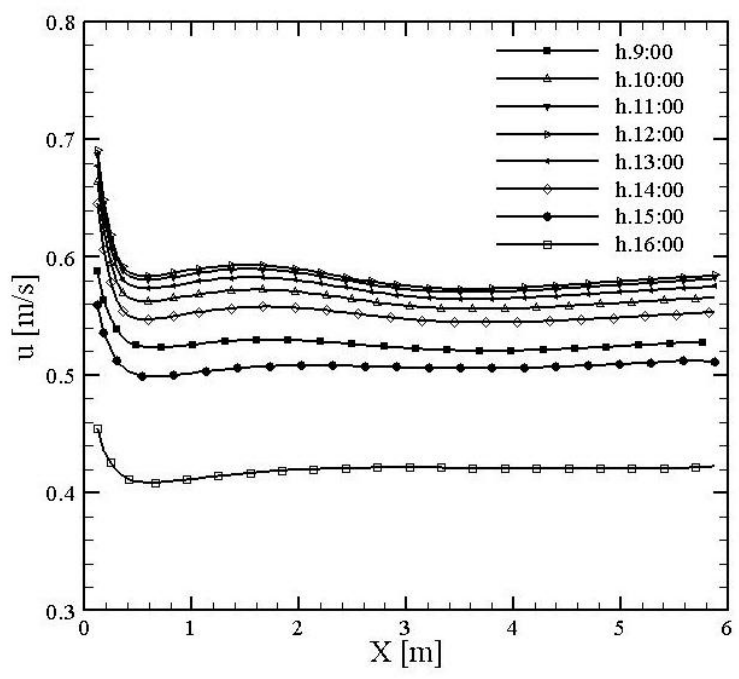

(b) Winter configuration

Figure 9. Velocity profiles in center line

Table 1. Thermofluidodynamic characteristics in summer condition

\begin{tabular}{cccccccc}
\hline Time & $\mathrm{q}_{\mathrm{s}}$ & $\mathrm{m}$ & $\mathrm{u}_{\text {avg }}$ & $\mathrm{u}_{\max }$ & $\mathrm{T}_{\text {avg }}$ & $\mathrm{T}_{\text {havg }}$ & $\mathrm{T}_{\max }$ \\
\hline & $\mathrm{W}^{2} \mathrm{~m}^{2}$ & $\mathrm{~kg} / \mathrm{s}$ & $\mathrm{m} / \mathrm{s}$ & $\mathrm{m} / \mathrm{s}$ & $\mathrm{K}$ & $\mathrm{K}$ & $\mathrm{K}$ \\
\hline $09: 00$ & 667 & 0.057 & 0.51 & 0.66 & 311.5 & 333.7 & 335.9 \\
\hline $10: 00$ & 782 & 0.061 & 0.55 & 0.72 & 313.1 & 338.9 & 341.3 \\
\hline $11: 00$ & 849 & 0.063 & 0.56 & 0.74 & 314.0 & 341.8 & 344.5 \\
\hline $12: 00$ & 862 & 0.064 & 0.57 & 0.75 & 314.2 & 342.3 & 345.1 \\
\hline $13: 00$ & 822 & 0.062 & 0.56 & 0.73 & 313.6 & 340.6 & 343.2 \\
\hline $14: 00$ & 730 & 0.059 & 0.53 & 0.70 & 312.4 & 336.6 & 338.9 \\
\hline $15: 00$ & 593 & 0.054 & 0.49 & 0.64 & 310,4 & 330.4 & 332.3 \\
\hline $16: 00$ & 422 & 0.045 & 0.41 & 0.53 & 307.8 & 322.5 & 323.6 \\
\hline $17: 00$ & 236 & 0.034 & 0.31 & 0.40 & 304.5 & 313.2 & 313.8 \\
\hline $18: 00$ & 85 & 0.018 & 0.17 & 0.22 & 310.4 & 305.1 & 305.2 \\
\hline
\end{tabular}

\section{CONCLUSIONS}

A numerical investigation is realized to know the thermal behavior of a prototypal ventilated roof for residential use under variable solar radiation, to simulate summer and winter conditions. The system is composed by a single side of the roof, due to its geometrical and thermal symmetry. The system consists of a ventilated cavity: on the bottom wall, a

Table 2. Thermofluidodynamic characteristics in winter condition

\begin{tabular}{cccccccc}
\hline Time & $\mathrm{q}_{\mathrm{w}}$ & $\mathrm{m}$ & $\mathrm{u}_{\text {avg }}$ & $\mathrm{u}_{\max }$ & $\mathrm{T}_{\text {avg }}$ & $\mathrm{T}_{\text {havg }}$ & $\mathrm{T}_{\max }$ \\
\hline & $\mathrm{W} / \mathrm{m}^{2}$ & $\mathrm{~kg} / \mathrm{s}$ & $\mathrm{m} / \mathrm{s}$ & $\mathrm{m} / \mathrm{s}$ & $\mathrm{K}$ & $\mathrm{K}$ & $\mathrm{K}$ \\
\hline $09: 00$ & 310 & 0.033 & 0.53 & 0.57 & 285.3 & 292.6 & 294.2 \\
\hline $10: 00$ & 410 & 0.040 & 0.57 & 0.64 & 286.7 & 297.6 & 299.8 \\
\hline $11: 00$ & 467 & 0.043 & 0.58 & 0.67 & 287.5 & 300.5 & 302.8 \\
\hline $12: 00$ & 478 & 0.044 & 0.59 & 0.68 & 287.7 & 300.8 & 303.4 \\
\hline $13: 00$ & 444 & 0.042 & 0.58 & 0.66 & 287.2 & 299.3 & 301.6 \\
\hline $14: 00$ & 365 & 0.037 & 0.54 & 0.62 & 286.0 & 295.5 & 297.3 \\
\hline $15: 00$ & 245 & 0.027 & 0.51 & 0.53 & 284.4 & 289.1 & 290.5 \\
\hline $16: 00$ & 81 & 0.001 & 0.42 & 0.44 & 280.0 & 282.0 & 287.6 \\
\hline
\end{tabular}

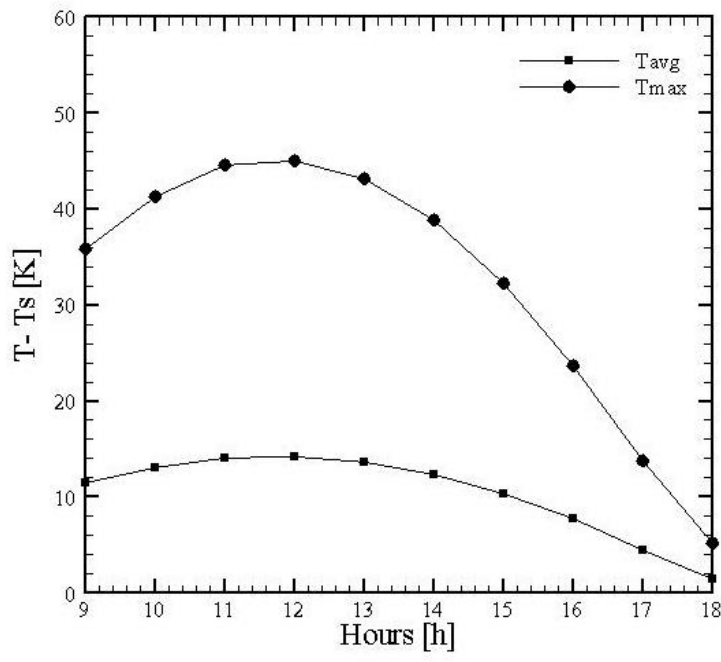

(a) Summer configuration

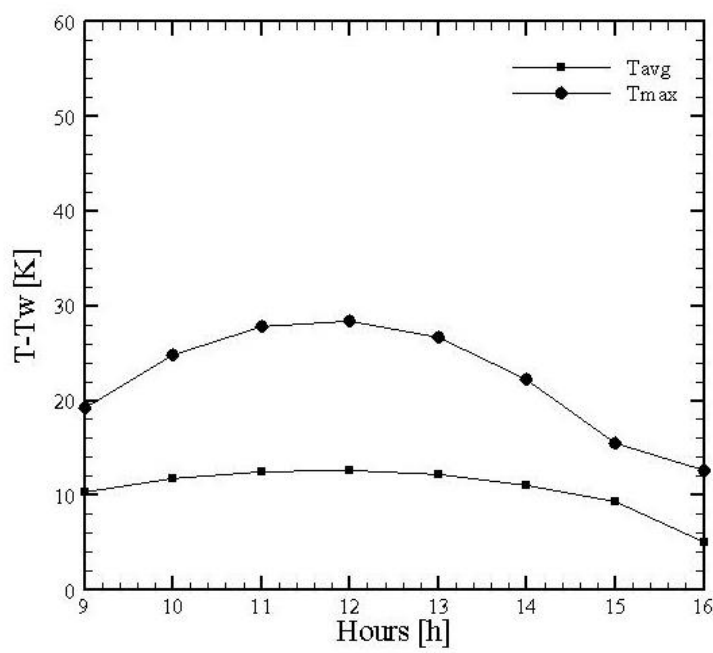

(b) Winter configuration

Figure 10. Average and maximum temperature profiles in the channel

constant value of temperature is applied to simulate optimal ambient condition in summer and winter periods; on the top wall, a heat flux is applied to simulate solar radiation operating at different hours on typical summer and winter days. In particular, analyzing the thermal behaviors, the study has revealed that:

- Temperature increases in the channel with the distance to the inlet section due to the effect on heat transfer and flow air in the channel. The maximum value is reached on the top wall of the cavity, where the effect of the solar radiation is more evident.

- Velocity increases in the channel because of the air heating, so in summer period values are higher. Maximum values are reached in the outlet reservoir, where a vortex increases velocity values in proximity of the ridge.

- $\quad$ Temperature trend is the same along five different cross sections, but higher values are reached at $x=5.0 \mathrm{~m}$. In summer, values increase in the channel; in winter, due to the bottom wall condition, temperature decreases at first, then maximum value is reached on the top wall of the cavity. 
- $\quad$ Along the channel, temperature trend is growing in each condition, but values are higher in summer period, when the effect of solar radiation is more evident thanks to the convective effect within the channel. In winter, the effect of the ventilated layer is very important to reach optimal thermal and hygrometric conditions.

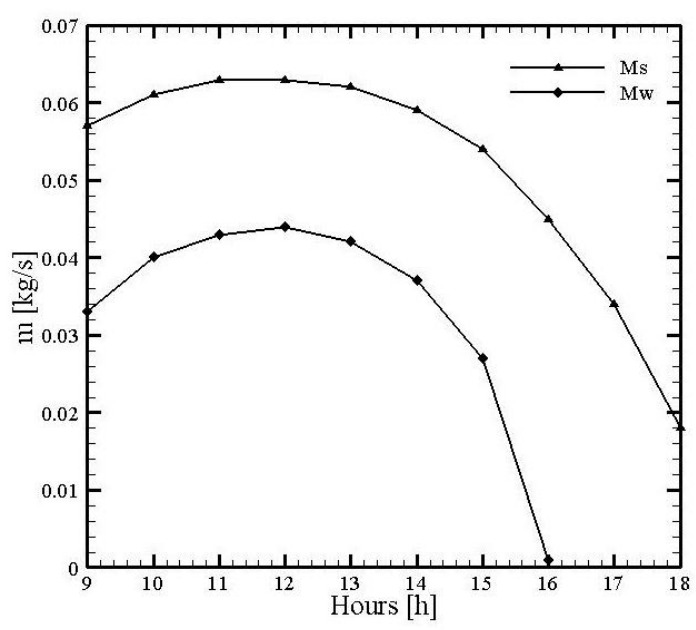

Figure 11. Mass flow rate in summer and winter conditions

\section{REFERENCES}

[1] Ciampi M., Leccese F., Tuoni G. (2005). Energy analysis of ventilated and microventilated roofs, Sol. Energy, Vol. 79, pp. 183-192. DOI: 10.1016/j.solener.2004.08.014

[2] Manca O., Mangiacapra A., Marino S., Nardini S. (2014). Numerical investigation on thermal behaviors of an inclined ventilated roof, $12^{\text {th }}$ Biennal Conference on Engineering Systems Design and Analysis ESDA2014, Copenhagen, Denmark.

[3] Tong Y., Zhai J., Wang C., Zhou B., Niu X. (2016). Possibility of using roof openings for natural ventilation in a shallow urban road tunnel, Tunn. Undergr. Sp. Tech., Vol. 54, pp. 92-101. DOI: 10.1016/j.tust.2016.02.004

[4] Lai C., Huang J.Y., Chiuo J.S. (2008). Optimal spacing for double-skin roofs, Build. Environ., Vol. 43, pp. 1749-1754. DOI: 10.1016/j.buildenv.2007.11.008

[5] Wong N.H., Li S. (2007). A study of the effectiveness of passive climate control in naturally ventilated residential buildings in Singapore, Build. Environ., Vol. 42, pp. 1395-1405. DOI: 10.1016/j.buildenv.2005.11.032

[6] Tong S., Li H. (2014). An efficient model development and experimental study for the heat transfer in naturally ventilated inclined roofs, Build. Environ., Vol. 81, pp. 296-308. DOI: 10.1016/j.buildenv.2014.07.009

[7] Ozdeniz M.B, Hancer P. (2015). Suitable roof constructions for warm climates - Gazimagusa case, Energ. Buildings, Vol. 37, pp. 643-649. DOI: 10.1016/j.enbuild.2004.09.008

[8] Zingre K.T, Wan M.P., Wong S.K., Toh W.B.T. (2015). Modelling of cool roof performance for double-skin roofs in tropical climate, Energy, Vol. 82, pp. 813-826. DOI: $10.1016 /$ j.energy.2015.01.092
[9] Biwole P.H., Woloszyn M., Pompeo C. (2008). Heat transfer in a double-skin roof ventilated by natural convection in summer time, Energ. Buildings, Vol. 40, pp. 1487-1497. DOI: 10.1016/j.enbuild.2008.02.004

[10] Dimoudi A., Androutsopoulos A., Lykoudis S. (2006). Summer performance of ventilated roof component, Energ. Buildings, Vol. 38, pp. 610-617. DOI: 10.1016/j.enbuild.2005.09.006

[11] Gagliano A., Patania F., Nocera F., Ferlito A., Galesi A. (2012). Thermal performance of ventilated roofs during summer period, Energ. Buildings, Vol. 49, pp. 611-618. DOI: $10.1016 /$ j.enbuild.2012.03.007

[12] Villi G., Pasut W., De Carli M. (2009). CFD modelling and thermal performance analysis of a wooden ventilated roof structure, Build. Simul., Vol. 2, pp. 215228. DOI: $10.1007 / \mathrm{s} 12273-009-9414-7$

[13] Dimoudi A., Lykoudis S., Androutsopoulos A. (2006). Thermal performance of an innovative roof component, Renew. Energ., Vol. 31, pp. 2257-2271. DOI: 10.1016/j.renene.2005.10.012

[14] Kosny J., Biswas K., Miller W., Kriner S. (2012). Field thermal performance of naturally ventilated solar roof with PCM heat sink, Sol. Energy, Vol. 86, pp. 25042514. DOI: $10.1016 /$ j.solener.2012.05.020

[15] Wang Y., Tian W., Ren J., Zhu L., Wang Q. (2006). Influence of building's integrated-photovoltaics on heating and cooling loads, Appl. Energ., Vol. 83, pp. 989-1003. DOI: $10.1016 /$ j.apenergy.2005.10.002

[16] Kharrufa S.N., Adil Y. (2012). Upgradng the building envelope to reduce cooling loads, Energ. Buildings, Vol. 55, pp. 389-396. DOI: 10.1016/j.enbuild.2012.09.006

[17] Bianco V., Diana A., Manca O., Nardini S. (2016). Thermal behavior evaluation of ventilated roof under variable solar radiation, Int. J. Heath Tech., Vol. 34, pp. 346-359.

[18] Handbook of Heat Transfer (1998). $3^{\text {rd }}$ ed., McGrawHill, USA.

[19] ANSYS-Fluent Inc. (2012). Ansys-Fluent 12.2 manuals, Ansys ed.

[20] Database PVGIS-CMSAF. Calcolo dell' irraggiamento solare, from http://www.consiglioenergia.it/joomla/utilita/calcola-1irraggiamento, accessed on 11 October 2016.

[21] Fluent-Inc. Gambit 2.4 Modeling Guide ed. 2007.

\section{NOMENCLATURE}

$\mathrm{b}$

Channel width, $\mathrm{m}$

h Hipped roof height, $m$

L Channel length, $\mathrm{m}$

$\mathrm{L}_{\mathrm{x}}, \mathrm{L}_{\mathrm{y}} \quad$ Inlet reservoir dimensions, $\mathrm{m}$

$\mathrm{h} \quad$ Height of the ridge, $\mathrm{m}$

$\mathrm{m} \quad$ Mass of air in the ventilated channel per unit of time, $\mathrm{kg} / \mathrm{s}$

$\mathrm{q}_{\mathrm{s}} \quad$ Heat flux in summer, $\mathrm{W} / \mathrm{m}^{2}$

$\mathrm{q}_{\mathrm{w}} \quad$ Heat flux in winter, $\mathrm{W} / \mathrm{m}^{2}$

$\mathrm{T} \quad$ Operative temperature, $\mathrm{K}$

$\mathrm{T}_{\mathrm{s}} \quad$ Temperature in summer regime, $\mathrm{K}$

$\mathrm{T}_{\mathrm{w}} \quad$ Temperature in winter regime, $\mathrm{K}$

$T_{\text {avg }} \quad$ average value of the temperature in the exit section of the channel, $\mathrm{K}$

$T_{\text {havg }} \quad$ average value of the temperature on the top wall of the ventilated channel, $\mathrm{K}$ 
$u_{\text {avg }}$

$u_{\text {max }}$ average value of the velocity in the ventilated channel, $[\mathrm{m} / \mathrm{s}]$

maximum value of the velocity in the ventilated channel, $[\mathrm{m} / \mathrm{s}]$
$X, Y, Z$ :

$\theta$

$\mathrm{k}$

$\varepsilon$
Cartesian coordinates

Roof inclination,

Kinetic energy of turbulence

Turbulent kinetic energy dissipation 